\title{
UMA ABORDAGEM SOCIOLINGUÍSTICA DA CONCORDÂNCIA NOMINAL DE NÚMERO NO FALAR DOS HABITANTES DO MUNICÍPIO AMAZONENSE DE BENJAMIN CONSTANT
}

\author{
A SOCIOLINGUISTIC APPROACH OF THE NUMBER-NOMINAL AGREEMENT IN \\ THE CITY AMAZONENSE OF BENJAMIN CONSTANT
}

\author{
Flávia Santos Martins \\ Doutoranda em Linguística- UFSC/ UFAM
}

\begin{abstract}
Resumo
Este artigo teve como objetivo investigar a Concordância Nominal de Número no falar dos habitantes do município de Benjamin Constant (AM). Para realização desta pesquisa foram controlados de forma sistemática os seguintes grupos de fatores independentes: extralinguísticos - a idade, o sexo, a escolaridade e o nível de formalidade, na busca de um melhor conhecimento sócio-cultural da área pesquisada, e linguísticos - a saliência fônica, a posição, a classe gramatical e o contexto seguinte. Os dados de elocução livre analisados mostram que os falantes do município investigado utilizam mais a não-concordância, variante considerada não-padrão e inovadora (57\%). A análise de grupos de fatores condicionantes realizada mostra os seguintes resultados: a $1^{a}$ posição ocupada no sintagma nominal é o elemento que mais privilegia o uso de marcas explícitas de plural, assim como os elementos determinantes à esquerda (artigo, numeral e pronome); a saliência fônica mostrou-se como um dos condicionadores que mais provocam a presença de marcas de plural; quando o contexto seguinte é vogal, em relação à pausa e às consoantes, há preservação da marca de plural; as mulheres tendem ao uso da norma padrão, portanto, fazem uso da concordância nominal e quanto à idade, os jovens utilizam com a mesma frequência tanto a variante inovadora (uso da não concordância) quanto a conservadora (uso da concordância), assim como os mais velhos.
\end{abstract}

Palavras-chave: Sociolinguística. Concordância Nominal de Número. Variação.

\begin{abstract}
This article has the objective of investigate the Nominal-Number Agreement of Benjamin Constant (AM) inhabitants' speech. To realize this research, the fallowing factors were controlled in a systematic manner: (a) extra linguistic factors- age, gender, scholar level and the level of formality, in order to obtain a better social-cultural knowledge of the researched area, and (b) linguistic - phonetical sharpness, position, grammatical class and the next context. The analyzed data of free elocution showed that the investigated city inhabitants' speech use more the non-agreement, considered the non standard variant and innovator (57\%). The cluster analysis of conditioning factors shows the following results: $1^{\mathrm{a}}$ position occupied in nominal prhase is the element that more privileges the use of explicit marks of plural, as well as the determinative elements to the left (article, numeral and pronoun); the phonetical salience has revealed itself as one of the conditioners that provokes more the presence of plural marks; when the following context is vowel, in relation to the pause and consonants, it presents the preservation of the plural mark; women tend to the use of norm standard, therefore, they
\end{abstract}


make use of the Nominal Agreement and concerning to age, young people in such a way uses both the innovative variant (use of not the agreement) with the same frequency and the conservative (use of the agreement), as well as the oldest.

Keywords: Sociolinguistics. Nominal-Number Agreement. Variation.

\section{INTRODUÇÃO}

Desde a década de 1970, pesquisas dialetais e sociolinguísticas vêm ganhando notoriedade no Brasil. Vários trabalhos sobre a variedade linguística do português brasileiro vêm sendo realizados a fim de sistematizar a heterogeneidade da língua falada que a princípio, segundo Tarallo (2003), é vista como um “caos”.

No Amazonas, não há uma tradição de trabalhos nessa área. Recentemente foi elaborado o Atlas Linguístico do Amazonas (ALAM) por Cruz (2004) como tese de doutorado, investigando a fala de nove municípios do Amazonas (Barcelos, Benjamim Constant, Eirunepé, Humaitá, Itacoatiara, Lábrea, Manacapuru, Parintins e Tefé) na perspectiva da Geolinguística e da Sociolinguística Variacionista, contribuindo, assim, para um melhor conhecimento do falar da região. Nessa pesquisa foram observados fenômenos fonéticofonológicos e semântico-lexicais.

Na região do Alto Solimões, especificamente, foi realizada apenas uma pesquisa de cunho dialetológico e sociolinguístico, por Cruz (2004), que, para a elaboração de sua tese, selecionou para cada microrregião ${ }^{1}$, em que o Amazonas é dividido politicamente, um município que a representasse. No caso da microrregião mencionada, a cidade de Benjamin Constant é que foi investigada. Há, então, nesse município, um registro fonético e lexical detalhado das variedades linguísticas do falar dessa região que abrange nove municípios: Amaturá, Atalaia do Norte, Benjamin Constant, Fonte Boa, Jutaí, São Paulo de Olivença, Santo Antônio do Içá, Tabatinga e Tonantins- situados na fronteira com Peru e Colômbia. É importante, assim, que se faça também um registro morfológico e sintático, sistematizado e científico das variedades linguísticas dessa região, especificamente de Benjamin Constant.

Durante a execução de trabalhos de iniciação científica, realizados por esta pesquisadora, e também de observações empíricas, algo que chama a atenção é o uso variável da concordância nominal, principalmente no que diz respeito à de número. $\mathrm{O}$ que se observa é uma tendência dos falantes em eliminar na fala, em uma situação informal (situação distensa, em que o falante não se preocupa em como falar), as marcas redundantes de plural (BAGNO, 2006), por exemplo: As menina Ø, As casas amarelaØ. O plural é marcado, em geral, apenas na primeira posição do sintagma nominal. Portanto, na fala é utilizada uma construção sintática diferente da estabelecida pela norma padrão.

Em um dos trabalhos realizados por esta pesquisadora, no Programa Institucional de Bolsas de Iniciação Científica (PIBIC), com a pesquisa intitulada "A pronúncia do -S

\footnotetext{
1 Agrupamento de municípios limítrofes. Sua finalidade é integrar a organização, o planejamento e a execução de funções públicas de interesse comum, definidas por lei complementar estadual.
} 
pós-vocálico nos municípios de Itacoatiara, Manacapuru, Parintins, Tefé, Barcelos e Benjamin Constant”, essa situação foi bem perceptível, apesar de o objetivo desse trabalho não ter sido o de analisar o -s morfema de plural. Dessa forma, surgiu o interesse de investigar a concordância de número no sintagma nominal, no falar dos habitantes de Benjamin Constant (Alto Solimões), observando a influência de alguns grupos de fatores extralinguísticos na fala espontânea, como sexo, idade e escolaridade e de grupos de fatores linguísticos, como a saliência fônica, a posição, a classe gramatical e o contexto seguinte. O tipo de sintagma nominal utilizado como dado de análise foi o com dois a três elementos: “dois bairroØ”, “os dois boiØ”, etc.

As hipóteses deste trabalho, formuladas com base em estudos sociolinguísticos, foram as seguintes:

a) O que se observa na fala espontânea é a eliminação das marcas de plural, ocorrendo apenas no determinante ou em elementos mais à esquerda do sintagma nominal, na primeira casa, geralmente (SCHERRE 1978; 1988). Ex.: "As meninaØ”;

b) Elementos mais salientes favorecem as marcas de plural explícitas (SCHERRE 1978; 1988). Ex: “os meses”;

c) Observa-se que quanto maior o grau de escolaridade do falante mais ele se aproxima das formas de prestígio (padrão), pois a escola é um dos ambientes que privilegia a norma linguística utilizada na escrita;

d) No que se refere ao contexto seguinte, a presença da vogal é um fator para que haja as marcas explícitas de plural;

d) Quanto à idade, espera-se que os mais jovens utilizem a forma considerada inovadora, ou seja, o uso não-padrão da concordância nominal, o que pode caracterizar uma mudança em tempo aparente;

e) Quanto ao sexo, as mulheres devem apresentar mais a concordância nominal padrão. Isso pode ser explicado pela inserção delas no mercado de trabalho e ao mesmo tempo pelo papel fundamental que exercem na família (essas situações acabam “exigindo” delas o uso da variante considerada padrão).

Para a pesquisa de Cruz (2004), foram coletados dados em forma de questionário (perguntas e respostas objetivas) e em forma de conversação livre. Cruz (2004) teve por objetivo analisar os dados de situação formal (perguntas e respostas), seguindo os princípios da Dialetologia para a elaboração de atlas.

Na pesquisa, cujos resultados são apresentados neste artigo, foi observado o fenômeno da concordância nominal de número em situação de conversação livre (situação informal), gravada na ocasião em que foram coletados os dados para a elaboração do ALAM, situação em que a pesquisadora procurou deixar o falante bem à vontade, fazendo com que falasse sobre algum fato de sua vida, festas, lendas e histórias interessantes da localidade. No ALAM, foram investigados 6 informantes por município, sendo 1 homem e 1 mulher, com nível de escolaridade no máximo até a $4^{\mathrm{a}}$ série, divididos em 3 faixas etárias: 18 a 35 anos, 36 a 55 anos, 56 em diante. Nesta pesquisa, foram utilizados os 6 informantes pertencentes ao município investigado. 
Com a realização deste trabalho foi possível conhecer um aspecto da variedade linguística de Benjamin Constant, contribuindo, assim, para o conhecimento das áreas dialetais brasileiras.

\section{FUNDAMENTAÇÃO TEÓRICA}

\subsection{Sobre a concordância nominal de número}

Uma das variantes linguísticas encontradas no falar do português brasileiro refere-se à presença de marcas de concordância nominal como em "os estudos sociolinguísticos" que em geral se alterna com a possibilidade de ocorrência de enunciados em que tais marcas estão ausentes: “os estudoØ sociolinguísticoØ”(MOLLICA, 2004).

Alguns trabalhos que abordam esse tema já foram realizados. Pode-se citar: Braga (1977) em um estudo no triângulo mineiro; Ponte (1979) ao estudar a concordância nominal de uma comunidade de Porto Alegre; Dias (1993) que faz um contraste entre o urbano e o rural na fala brasiliense; Lobato (1994) que estuda a concordância de número nominal à luz da teoria de princípios-e-parâmetros e da sociolinguística variacionista.

Um dos trabalhos de maior referência no Brasil e que foi o principal aparato desta pesquisa é o de Maria Marta Scherre. Seus principais estudos foram: "A regra de concordância de número no sintagma nominal em português”, em 1978, como dissertação de mestrado; e "Reanálise da concordância nominal em português", em 1988, como tese de doutorado.

Naro \& Scherre (1998) mostram que a concordância de número no português apresenta uma variação sistemática, exibindo variantes explícitas e variante zero (Ø) de plural em elementos verbais e nominais. Eles procuram correlacionar variáveis linguísticas (saliência fônica e posição) e sociais (anos de escolarização, sexo e faixa etária).

Os resultados de suas pesquisas evidenciam que elementos fonicamente mais salientes (acentuados) favorecem as marcas explícitas de plural; elementos não nucleares à esquerda do núcleo favorecem marcas explícitas; elementos não nucleares à direita do nome desfavorecem-nas. Os núcleos, por sua vez, favorecem mais marcas explícitas se ocuparem a primeira posição na cadeia sintagmática, ou seja, se estiverem linearmente mais à esquerda na construção sintática; apresentam mais a variante explícita as pessoas com mais anos de escolarização e as do sexo feminino. Aquelas por estarem mais expostas à correção gramatical e estas, como outras pesquisas já atestam, por não "romperem" as regras sociais estabelecidas, sendo, em particular, mais sensíveis às normas de prestígio; a variável faixa etária apresenta um padrão ligeiramente curvilinear, indicando que as pessoas mais pressionadas pela idade profissionalmente produtiva usam também mais as formas de prestígio.

Estudos anteriores ao de Naro \& Scherre (1998) quanto à variável linguística saliência fônica mostram resultados envolvendo o fator classe social:

Braga \& Scherre (apud SCHERRE, 1988) concluem que as formas mais salientes favorecem mais marcas de plural do que as formas menos salientes. Verificam que a 
escala da saliência é mais evidente nos falantes de classe média e média alta do que nos de classe baixa, embora ocorra nos três grupos.

Braga (apud SCHERRE, 1988), trabalhando com o português do Triângulo mineiro da classe média e baixa, retoma esta variável com as mesmas categorias e conclui também que a classe média mineira apresenta resultados probabilísticos favorecedores da presença da concordância em função do grau de saliência fônica, da mesma forma estabelecida em Braga \& Scherre (apud SCHERRE,1988).

Esta pesquisa procurou, a partir do aprofundamento desse referencial teórico, descrever e analisar o falar dos habitantes do alto Solimões (Amazonas) no que diz respeito à concordância de número no sintagma nominal.

\section{RESULTADOS}

Os dados encontrados e analisados nesta pesquisa foram apenas 68 ocorrências de sintagmas nominais produzidas pelos 6 informantes do município de Benjamin Constant (AM). A análise da variável em estudo (concordância nominal de número) permitiu chegar ao seguinte resultado geral:

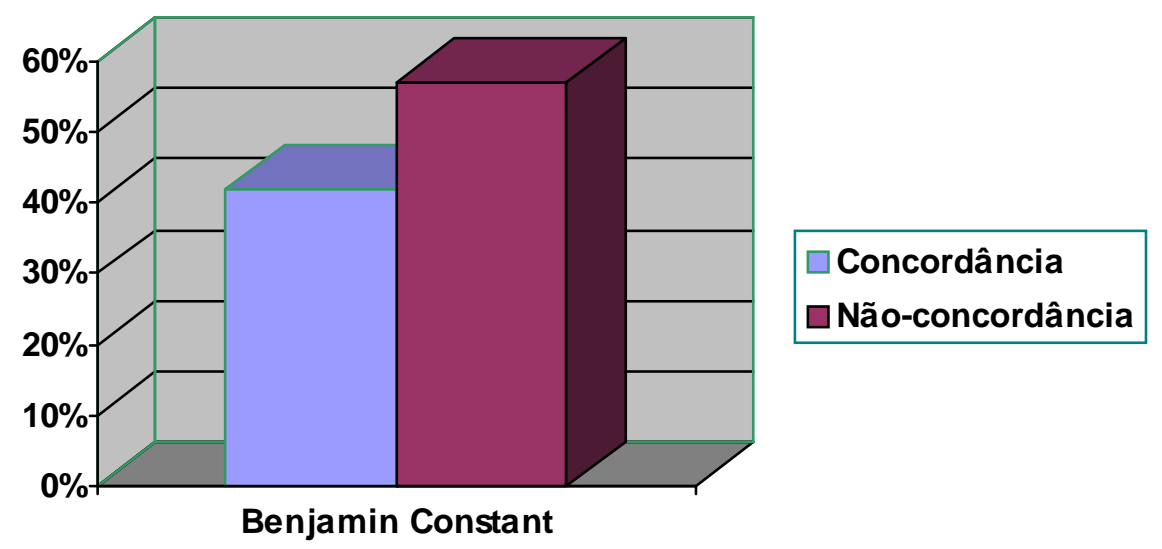

GRÁFICO 1: Distribuição da variável concordância nominal de número em Benjamin Constant

Como se observa, o falar dos habitantes desse município apresenta a variante nãoconcordância (57\%), considerada não-padrão, com maior predominância. Vale lembrar, o nível de escolaridade dos informantes analisados era até, no máximo, a $4^{\text {a }}$ série, o que atesta a hipótese de que pessoas menos escolarizadas utilizem mais a norma não-padrão.

Nas próximas seções, segue a análise dos grupos de fatores: variáveis linguísticas (posição, saliência fônica, classe gramatical e contexto seguinte) e extralinguísticas (idade, sexo e escolaridade). 


\subsection{Variáveis linguísticas}

\subsubsection{Posição no sintagma nominal}

Para a variável posição no sintagma nominal, segundo a hipótese levantada nesta pesquisa, o que se observa em alguns estudos já realizados como o de Scherre (1978; 1988) é que na fala espontânea há a eliminação das marcas de plural, ocorrendo apenas em elementos mais à esquerda do sintagma nominal, na primeira casa, geralmente. A seguir, os resultados desta pesquisa:

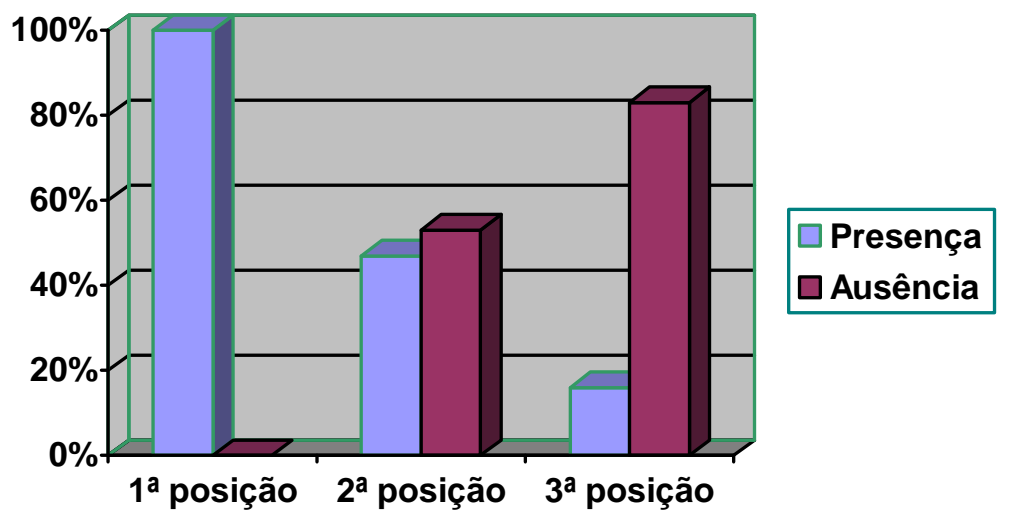

GRÁFICO 2: Presença e ausência de marca de plural nos elementos do sintagma nominal quanto à posição

O que se observa é que a primeira posição ocupada no sintagma nominal apresenta categoricamente a marca de plural, por exemplo: “os carro...” (BENJ $001 \mathrm{AF}^{2}$ ), “as pessoa...” (BENJ $002 \mathrm{BF})$. A $2^{\mathrm{a}}$ posição apresenta mais a ausência de marcas de plural (53\%), enquanto a $3^{\mathrm{a}}$ posição é o elemento que menos preserva a marca de plural (16\%). Por exemplo: “os dois boi...” (BENJ $001 \mathrm{AF})$, “meus filho mesmo...” (BENJ $002 \mathrm{BF).}$

Esses dados evidenciam a hipótese de que os elementos mais à esquerda do sintagma nominal apresentam mais a marca de plural.

\subsubsection{Saliência Fônica}

No que se refere à variável saliência fônica, algumas pesquisas mostram que os elementos mais salientes favorecem as marcas de plural explícitas (SCHERRE 1978; 1988). Segue abaixo, os resultados desta pesquisa:

\footnotetext{
${ }^{2}$ Para 001 AM lê-se: $1^{\text {a }}$ faixa etária masculino (18 a 35 anos); para 001 AF: $1^{\text {a }}$ faixa etária feminino; para 002 BM: $2^{\mathrm{a}}$ faixa etária masculino (36 a 55 anos); para $002 \mathrm{BF}$ : $2^{\mathrm{a}}$ faixa etária feminino; para $003 \mathrm{CM}$ : $3^{\mathrm{a}}$ faixa etária masculino (56 em diante) e para 003 CF: $3^{\text {a }}$ faixa etária feminino.
} 


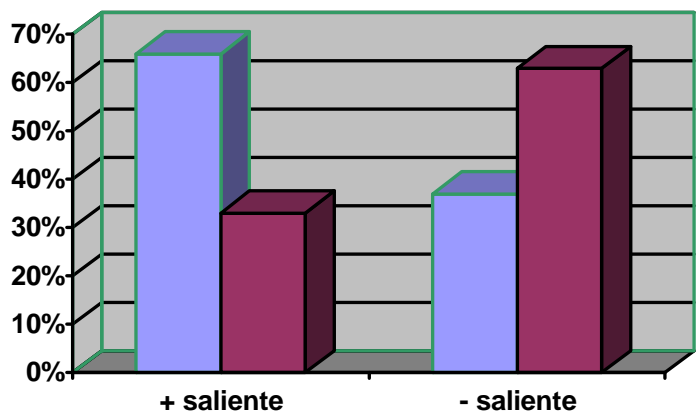

GRÁFICO 3: Presença e ausência de marca de plural no sintagma nominal quanto à saliência fônica

Os dados acima mostram que o aumento de material fônico na oposição singular/ plural aumenta as chances de concordância nominal (66\%), corroborando a hipótese postulada nesta pesquisa: "sete meses" (BENJ $003 \mathrm{CF}$ ), “às vezes..." (BENJ $001 \mathrm{AF}$ ), "sete meses...” (BENJ 003CF) “duas noiteØ..” (BENJ 001 AF), “os brincanteØ...” (BENJ $001 \mathrm{AF})$.

\subsubsection{Classe Gramatical}

Quanto à classe gramatical, observam-se nas pesquisas realizadas sobre variação no sintagma nominal no que se refere à concordância de número que elementos determinantes, como artigo, numeral e pronome, recebem a marca explícita de plural.

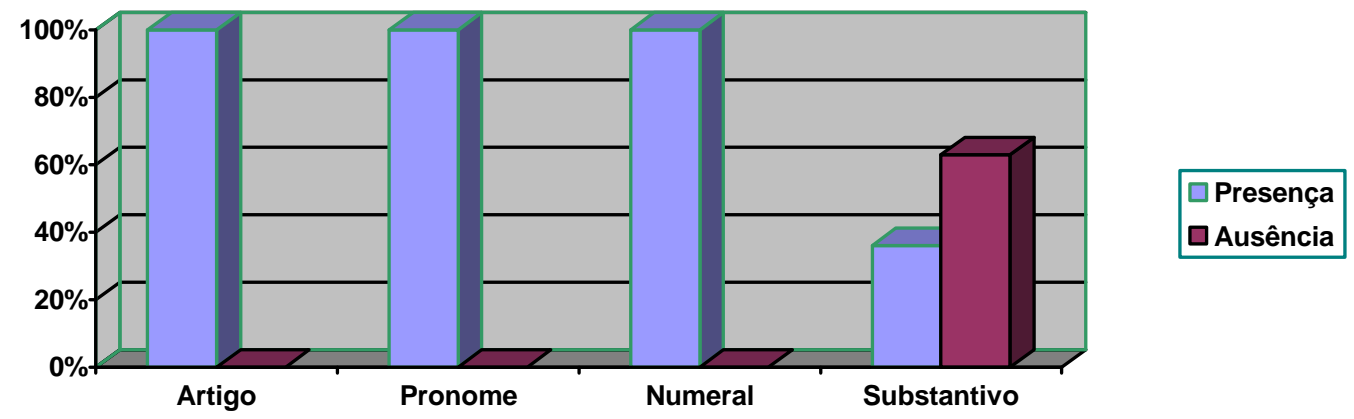

GRÁFICO 4: Presença e ausência de marca de plural no sintagma nominal quanto à classe gramatical

Como se observa, quanto à classe gramatical os elementos determinantes (artigo, pronome e numeral) tendem a receber mais marcas explícitas de plural (100\%) do que os elementos nucleares (substantivo- 36\%), por exemplo: “os grito...” (BENJ 001 AF) "as nuvem..." (BENJ 001 AM), “daquelas antiga” (BENJ 003 CF), "fazia aqueles passo rodava lá" (BENJ $001 \mathrm{AF})$, "meus filho mesmo..." (BENJ $002 \mathrm{BF}$ ), "três ano" (BENJ 003 CF), “oitenta e quatro vez...” (BENJ 001 AM), “dois mês...” (BENJ 001 AM). Esses dados, portanto, atestam a hipótese levantada nesta pesquisa. 


\subsubsection{Contexto seguinte}

No que se refere ao contexto, geralmente, segundo pesquisas realizadas sobre a variação na concordância nominal de número, o que condiciona a utilização de marcas de plural é aquele que apresenta vogal após o primeiro elemento.

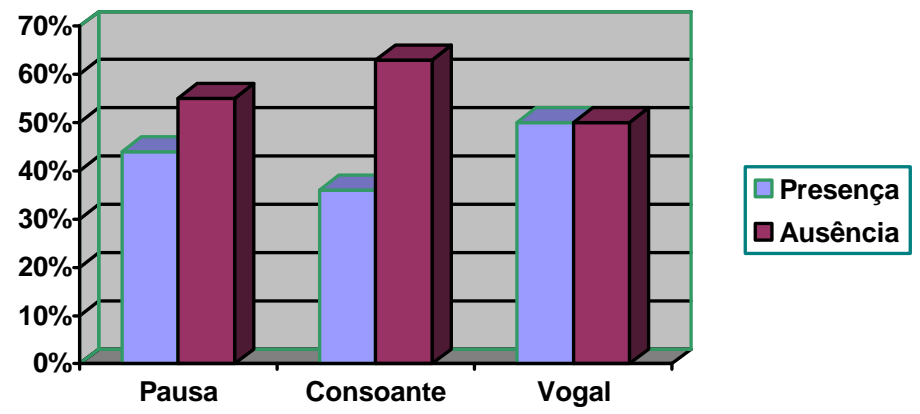

GRÁFICO 5: Presença e ausência de marca de plural no sintagma nominal quanto ao contexto seguinte do elemento de $2^{\mathrm{a}}$ posição (não-numeral)

No que se refere ao contexto seguinte, a vogal mostrou-se mais favorecedora da presença de marcas de plural (50\%) em relação à pausa (44\%) e à consoante (36\%), por exemplo: "as pessoaØ...” (BENJ 002 BF), "seis anoØ...” (BENJ 002 BM), "quatro pessoaØ moravam” (BENJ $001 \mathrm{AM}$ ), “fazia aqueles passoØ rodava lá” (BENJ 001 AF), "outras coisas assim” (BENJ 002 BF), "às vezes a..." (BENJ 001 AF). Esses dados, porém não evidenciam a hipótese de que predominantemente a vogal é o contexto que condiciona essa variante, pois a distribuição das duas variantes (presença X ausência) não demonstrou predominância de uma sobre a outra.

\subsection{Variáveis extralinguísticas}

\subsubsection{Gênero/ sexo}

Conforme a hipótese levantada nesta pesquisa, quanto ao sexo as mulheres apresentam mais o uso da variante padrão, ou seja, fazem uso da concordância nominal de número.

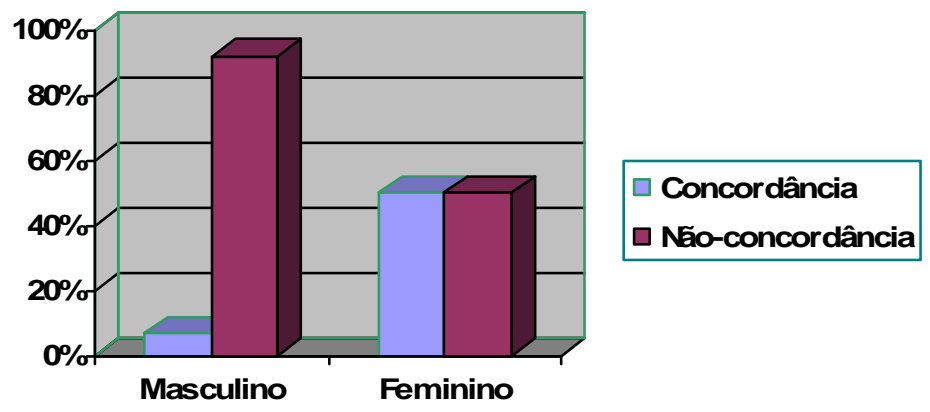

GRÁFICO 6: Distribuição da variável concordância nominal de número quanto ao sexo 
Quanto ao sexo, conforme os resultados desta pesquisa, as mulheres tendem a usar mais a concordância do que os homens (50\% e 7\%, respectivamente), o que corrobora a hipótese formulada nesta pesquisa que segue os resultados dos estudos sociolinguísticos.

\subsubsection{Idade}

Quanto à idade, a hipótese levantada nesta pesquisa é a de que os mais jovens utilizem a forma considerada inovadora, ou seja, o uso não-padrão da concordância nominal. O que caracteriza uma mudança em tempo aparente.

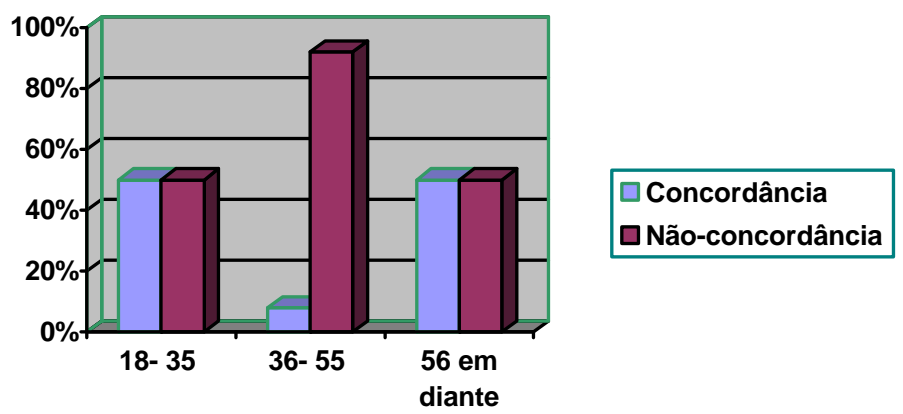

GRÁFICO 7: Distribuição da variável concordância nominal de número quanto à idade

No que se refere à idade, esta pesquisa evidenciou que os informantes de $2^{\text {a }}$ faixa etária são os que menos utilizam a concordância (8\%). Os de $1^{\mathrm{a}}$ e $3^{\mathrm{a}}$ faixa etária utilizam as duas variantes de forma homogênea (50\%), demonstrando que não há mudança em tempo aparente. Esses dados não evidenciam, dessa forma, a hipótese levantada nesta pesquisa, pois os mais jovens não utilizaram com maior frequência a variante considerada inovadora.

\section{CONSIDERAÇÕES FINAIS}

A investigação da concordância nominal de número no município de Benjamin Constant permitiu um registro mais sistematizado de uma das variáveis linguísticas utilizadas nessa região, contribuindo, dessa forma, para um melhor conhecimento das áreas dialetais brasileiras.

Através da descrição e análise dos grupos de fatores linguísticos e não linguísticos controlados nesta pesquisa, percebeu-se a sistematicidade que rege a variação na concordância nominal de número na fala dos habitantes de Benjamin Constant (Alto Solimões), evidenciando, portanto, que a língua apresenta uma heterogeneidade ordenada: a variação é inerente ao sistema linguístico.

Quanto aos grupos de fatores linguísticos, conforme os resultados discutidos no item anterior, a $1^{\mathrm{a}}$ posição ocupada no sintagma nominal é o elemento que mais privilegia 0 uso de marcas explícitas de plural, assim como os elementos determinantes à esquerda (artigo, numeral e pronome). A saliência fônica mostrou-se como um dos condicionadores que mais provocam a presença de marcas de plural (vale ressaltar que 
foram encontrados poucos elementos com marcas salientes de plural, no caso substantivos que marcam o plural em -es). Quando o contexto seguinte é vogal, em relação à pausa e às consoantes, há preservação da marca de plural, embora não seja de maneira categórica.

Quanto aos grupos de fatores não linguísticos, evidenciou-se que as mulheres tendem ao uso da norma padrão, portanto, fazem uso da concordância nominal. Isso costuma ser explicado, no âmbito das pesquisas sociolinguísticas, pelo papel conservador que exercem na sociedade. Quanto à idade, não se observou uma mudança em tempo aparente, pois os jovens utilizam com a mesma frequência tanto a variante inovadora (uso da não concordância) quanto a conservadora (uso da concordância), assim como os mais velhos. O que chama a atenção nos dados analisados, é que os informantes da $2^{a}$ faixa etária utilizam com maior predominância a variante não-padrão (nãoconcordância) e o que se esperava é que por ser a faixa que está inserida no mercado de trabalho fizessem mais uso da variedade padrão. Essa situação pode ser explicada por se tratar de informantes de baixo nível de escolaridade (até a $4^{\mathrm{a}}$ série), portanto marcada pelo distanciamento da norma padrão.

Enfim, os dados de elocução livre (situação mais informal), analisados, mostram que o município investigado utiliza mais a não-concordância, variante considerada não-padrão e inovadora (57\%). A análise de grupos de fatores condicionantes realizada nesta pesquisa nos permite prever, de certa forma, em quais contextos linguísticos e não linguísticos a marca de plural tenderá a ocorrer, alcançando, portanto, os objetivos propostos.

\section{REFERÊNCIAS}

BRAGA, M. L. A concordância de número no sintagma nominal no triângulo mineiro. Rio de Janeiro: PUC. Dissertação de Mestrado, 1977.

BAGNO, M. A Língua de Eulália: uma novela sociolinguística. São Paulo: Contexto, 2006.

CALVET, L-J. Sociolinguística: Uma Introdução Crítica. Tradução: Marcos Marcionilo. São Paulo: Parábola, 2002.

CRUZ, M. L. de C.. Atlas Linguístico do Amazonas - ALAM. Rio de Janeiro: UFRJ, Tese de Doutorado em Letras Vernáculas. 2 sem. 2004.

DIAS, M. C. A. C. A variação na concordância nominal: um contraste entre o urbano e o rural na fala brasiliense. Brasília: UnB. Dissertação de Mestrado, 1993.

LABOV, W. Padrões Sociolinguísticos. Tradução: Marcos Bagno, Maria Marta Pereira Scherre, Caroline Rodrigues Cardoso. São Paulo: Parábola, 2008.

LOBATO, L. M. P. A concordância nominal no português do Brasil à luz da teoria de princípios-e-parâmetros e da sociolinguística variacionista, 1994. 
MOLLICA, M. C.; BRAGA, M. L. (orgs). Introdução à Sociolinguística: o tratamento da variação. São Paulo: Contexto, 2004.

NARO \& SCHERRE, M. M. P A. Sobre a concordância de número no português falado do Brasil. In Ruffino, Giovanni (org.) Dialettologia, geolinguistica, sociolinguistica.(Atti del XXI Congresso Internazionale di Linguistica e Filologia Romanza) Centro di Studi Filologici e Linguistici Siciliani, Universitá di Palermo. Tübingen: Max Niemeyer Verlag, 5:509-523, 1998.

PONTE, V. M. L. A concordância nominal de uma comunidade de Porto Alegre. Rio Grande do Sul: PUC. Dissertação de Mestrado, 1979.

PRETI, D. (org.). Análise de Textos Orais. São Paulo: FFLCH, 1993.

Sociolinguística: Os Níveis de Fala: Um estudo sociolinguístico do diálogo na Literatura Brasileira. 7. ed. São Paulo: Editora da Universidade de São Paulo, 1994.

SCHERRE, M. M. P. A regra de concordância de número no sintagma nominal de Porto Alegre. Rio de Janeiro: PUC. Dissertação de Mestrado, 1978.

Reanálise da concordância nominal em português, Rio de Janeiro:

UFRJ. Tese de Doutorado, 1988.

TARALlO, F. A Pesquisa Sociolinguística. 7. ed. São Paulo: Ática, 2003. 
ANEXO

Normas para Transcrição Grafemática

\begin{tabular}{|c|c|c|}
\hline Ocorrências & Sinais & Exemplificação \\
\hline $\begin{array}{l}\text { Incompreensão de palavras } \\
\text { ou segmentos }\end{array}$ & ( & $\begin{array}{l}\text { do nível da renda... ( ) nível de } \\
\text { renda nacional. }\end{array}$ \\
\hline Hipótese do que se ouviu & (hipótese) & $\begin{array}{l}\text { (estou) meio preocupado (com o } \\
\text { gravador) }\end{array}$ \\
\hline $\begin{array}{l}\text { Truncamento (havendo } \\
\text { homografia, usa-se acento } \\
\text { indicativo da tônica e/ou } \\
\text { timbre) }\end{array}$ & I & e comé/ e reinicia \\
\hline Entonação enfática & maiúscula & porque as pessoas reTÊM moeda \\
\hline $\begin{array}{l}\text { Prolongamento de vogal e } \\
\text { consoante (como s, r) }\end{array}$ & $\begin{array}{c}\text { :: podendo } \\
\text { aumentar :::: } \\
\text { ou mais }\end{array}$ & $\begin{array}{llll}\text { ao emprestarem } & \text { os... } & \text { éh::.... } & \text { o } \\
\text { dinheiro... } & & & \end{array}$ \\
\hline Silabação & - & por motivo tran-sa-ção \\
\hline Interrogação & ? & e o Banco... Central... certo? \\
\hline Qualquer pausa & $\ldots$ & $\begin{array}{l}\text { são três motivos... ou três razões... } \\
\text { que fazem com que se retenha } \\
\text { moeda... existe uma... retenção }\end{array}$ \\
\hline $\begin{array}{l}\text { Comentários descritivos do } \\
\text { transcritor }\end{array}$ & ((minúscula)) & $(($ tossiu $))$ \\
\hline $\begin{array}{l}\text { Comentários que quebram } \\
\text { a seqüência temática da } \\
\text { exposição; desvio temático. }\end{array}$ & $\begin{array}{ll}-- \\
--\end{array}$ & $\begin{array}{l}\text {... a demanda de moeda -- vamos } \\
\text { dar essa notação -- demanda de } \\
\text { moeda por motivo }\end{array}$ \\
\hline $\begin{array}{l}\text { Superposição, } \\
\text { simultaneadade de vozes }\end{array}$ & $\begin{array}{l}\text { Ligando as } \\
\text { linhas }\end{array}$ & 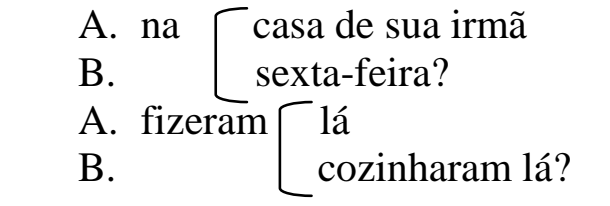 \\
\hline $\begin{array}{l}\text { Indicação de que a fala foi } \\
\text { tomada ou interrompida em } \\
\text { determinado ponto. Não no } \\
\text { seu início, por exemplo. }\end{array}$ & $(\ldots)$ & (...) nós vimos que existem... \\
\hline $\begin{array}{l}\text { Citações literais ou leituras } \\
\text { de textos, durante a } \\
\text { gravação. }\end{array}$ & “” & $\begin{array}{l}\text { Pedro Lima... ah escreve na } \\
\text { ocasião... “O cinema falado em } \\
\text { língua estrangeira não precisa de } \\
\text { nenhuma baRREira entre nós”... }\end{array}$ \\
\hline
\end{tabular}

